\title{
Channelopathies in Idiopathic Epilepsy
}

\author{
Sarah E. Heron, ${ }^{*}$ Ingrid E. Scheffer, ${ }^{\dagger \dagger}$ Samuel F. Berkovic ${ }^{\dagger}$ Leanne M. Dibbens, ${ }^{*}$ and \\ John C. Mulley*II \\ *Department of Genetic Medicine, Women's and Children's Hospital, North Adelaide, South Australia 5006; ${ }^{\dagger}$ Department of \\ Medicine (Neurology), The University of Melbourne and Austin Health, Heidelberg, Melbourne, Victoria 3081; ${ }^{\ddagger}$ Department of \\ Paediatrics, The University of Melbourne, Royal Children's Hospital, Parkville, Melbourne, Victoria 3052; ${ }^{\S}$ Department of \\ Paediatrics, University of Adelaide, Adelaide, South Australia 5005; and "IShool of Molecular and Biomedical Science, \\ University of Adelaide, Adelaide, South Australia 5005, Australia
}

\begin{abstract}
Summary: Approximately $70 \%$ of all patients with epilepsy lack an obvious extraneous cause and are presumed to have a predominantly genetic basis. Both familial and de novo mutations in neuronal voltage-gated and ligand-gated ion channel subunit genes have been identified in autosomal dominant epilepsies. However, patients with dominant familial mutations are rare and the majority of idiopathic epilepsy is likely to be the result of polygenic susceptibility alleles (complex epilepsy). Data on the identity of the genes involved in complex epilepsy is currently sparse but again points to neuronal ion channels. The number of genes and gene families associated with epilepsy is rapidly increasing and this increase is likely to escalate over the coming years with advances in mutation detection
\end{abstract}

technologies. The genetic heterogeneity underlying idiopathic epilepsy presents challenges for the rational selection of therapies targeting particular ion channels. Too little is currently known about the genetic architecture of the epilepsies, and genetic testing for the known epilepsy genes remains costly. Pharmacogenetic studies have yet to explain why $30 \%$ of patients do not respond to the usual antiepileptic drugs. Despite this, the recognition that the idiopathic epilepsies are a group of channelopathies has, to a limited extent, explained the therapeutic action of the common antiepileptic drugs and has assisted clinical diagnosis of some epilepsy syndromes. Key Words: Epilepsy, channelopathy, ion channel, seizure.

\section{INTRODUCTION}

The epidemiology of epilepsy is generally plagued by variations in diagnostic accuracy and ascertainment. However, in developed countries, incidence is generally accepted to be around $0.05 \%$ per year, prevalence of active epilepsy accepted as around $0.4 \%$ to $1.0 \%$, and lifetime prevalence approaches $5 \%{ }^{1}{ }^{\text {The }}$ large discrepancy between lifetime prevalence and active epilepsy is accounted for mainly by spontaneous remission. However, about $30 \%$ of patients are chronic sufferers who do not respond to antiepileptic drugs (AEDs). Although the phenotypic heterogeneity of epilepsy has long been apparent in the clinic, the degree of genetic heterogeneity is now being documented by ongoing discovery of new epilepsy genes for the same syndromes.

Address correspondence and reprint requests to: Sarah E. Heron, Department of Genetic Medicine, Women's and Children's Hospital, 72 King William Road, North Adelaide SA 5006, Australia; E-mail: sarah.heron@cywhs.sa.gov.au.

\section{IDIOPATHIC EPILEPSY}

Approximately $30 \%$ of patients with epilepsy have a known acquired cause, such as head trauma, stroke, tumor, or congenital lesion, ${ }^{2}$ while the remaining $70 \%$ include cases with the electroclinically defined "idiopathic" epilepsies, where genetic factors are believed to be central, as well as other less well defined syndromes. The monogenic autosomal dominant epilepsies are clearly genetic by the inspection of segregation patterns whereas a genetic component for the complex idiopathic epilepsies, idiopathic generalized epilepsy (IGE), certain focal epilepsies, and generalized epilepsy with febrile seizures plus $\left(\mathrm{GEFS}^{+}\right)$can be inferred from twin studies ${ }^{3}$ and the decay of risk beyond first degree relatives. Complex epilepsy has both polygenic and environmental components, as opposed to monogenic epilepsy predominantly caused by defects within single genes.

The "monogenic" and complex idiopathic epilepsies merge into a continuum from the fully penetrant monogenic epilepsies to those caused by less penetrant alleles of large effect, polygenic alleles of small effect, and 


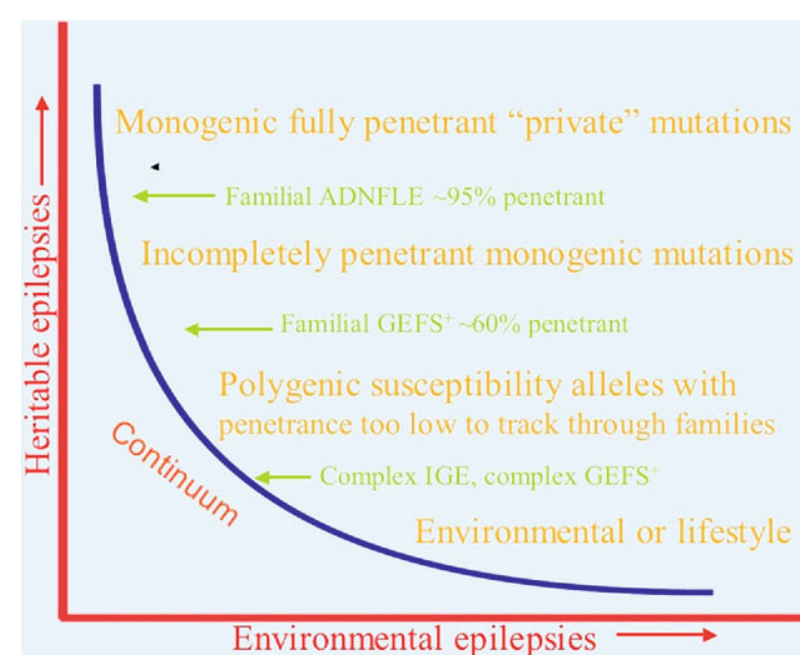

FIG. 1. Representation of the continuity between pure monogenic and pure environmental epilepsies.

finally, environmental effects with no genetic component (FIG. 1). The monogenic idiopathic epilepsies (Table 1) are relatively rare compared with the common or com- plex epilepsies; however, these rare large families have provided an entrée into the complex epilepsies, to provide what is so far proving to be the way forward into the unraveling of their genetic architecture.

\section{THE FAMILY OF CHANNELOPATHIES IN IDIOPATHIC EPILEPSY}

Table 1 shows the chronologic unfolding of the channelopathy story, as reviewed elsewhere ${ }^{4-7}$ and with subsequent additions. The initial discoveries of CHRNA4, $K C N Q 2, K C N Q 3$, and $S C N 1 B$ in epilepsy established the channelopathy pattern. This pattern has continued for the monogenic epilepsies with the addition of SCN1A, CHRNB2, GABRG2, SCN2A, GABRA1, CLCN2, and $C H R N A 2$ as well as a gene coding for a protein that forms part of an ion channel complex, LGI1, and EFHCI for which the relationship to ion transport is unclear. The channelopathy pattern has begun to spill over into the complex epilepsies with the identification of the suscep-

TABLE 1. Genes and Susceptibility Loci for Monogenic and Complex Epileptic Channelopathies

\begin{tabular}{|c|c|c|}
\hline Gene & Syndrome & Year of Discovery \\
\hline \multicolumn{3}{|c|}{ Monogenic channelopathies: } \\
\hline CHRNA4 & ADNFLE & 1995 \\
\hline$K C N Q 2$ & BFNS & 1998 \\
\hline$K C N Q 3$ & BFNS & 1998 \\
\hline$S C N 1 B$ & $\mathrm{GEFS}^{+}$ & 1998 \\
\hline SCN1A & $\mathrm{GEFS}^{+} /(\mathrm{SMEI})$ & $2000 /(01)$ \\
\hline CHRNB2 & ADNFLE & 2000 \\
\hline$G A B R G 2$ & $\mathrm{CAE} / \mathrm{FS} / \mathrm{GEFS}^{+}$ & 2001 \\
\hline$S C N 2 A$ & $\mathrm{GEFS}^{+} ? / \mathrm{BFNIS}$ & $2001 / 02$ \\
\hline GABRAl & ADJME, CAE & 2002/06 \\
\hline CLCN2 & IGE & 2003 \\
\hline CHRNA2 & ADNFLE & 2006 \\
\hline \multicolumn{3}{|c|}{ Monogenic, closely aligned with channelopathies: } \\
\hline LGI1 & ADPEAF & 2002 \\
\hline \multicolumn{3}{|c|}{ Monogenic, relationship to ion transport unclear: } \\
\hline EFHC1 & JME & 2004 \\
\hline \multicolumn{3}{|c|}{ Monogenic, associated with other paroxysmal disorders: } \\
\hline CACNA1A & CPS, GTCS & 2004 \\
\hline ATP1A2 & BFIS & 2003 \\
\hline \multicolumn{3}{|c|}{ Complex, components of polygenic channelopathies: } \\
\hline CACNAIH & CAE, IGE & 2003/04 \\
\hline$G A B R D$ & $\mathrm{IGE}, \mathrm{GEFS}^{+}$ & 2004 \\
\hline$K C N D 2$ & TLE & 2006 \\
\hline GABRB3 & CAE & 2006 \\
\hline
\end{tabular}

Genes: CHRNA4, acetylcholine receptor subunit, $\alpha 4 ; K C N Q 2 / K C N Q 3$, potassium channel subunits; $S C N 1 B$, sodium channel $\beta 1$ subunit; $S C N 1 A$, sodium channel $\alpha 1$ subunit; $C H R N B 2$, acetylcholine receptor subunit, $\beta 2 ; G A B R G 2$, GABA $_{\mathrm{A}}$ receptor subunit $\gamma 2 ; S C N 2 A$, sodium channel $\alpha 2$ subunit; GABRA1, GABA A $_{\mathrm{A}}$ receptor subunit $\alpha 1 ; C L C N 2$, chloride channel gene 2; CHRNA2, acetylcholine receptor subunit $\alpha 2$; $L G I 1$, leucine-rich, glioma inactivated 1 gene; $E F H C 1$, protein with an EF-hand motif; CACNA1A, $\alpha$ subunit of the P/Q type calcium channel; $A T P 1 A 2, \alpha 2$ subunit of the $\mathrm{Na}^{+} / \mathrm{K}^{+}$transporting ATPase; CACNA1H, Ca 3.2 T-type calcium channel; GABRD, GABA ${ }_{\mathrm{A}}$ receptor subunit $\delta ; K C N D 2, \mathrm{~K}_{\mathrm{v}} 4.2 \alpha$ subunit voltage-gated potassium channel of the shal subfamily; GABRB3, GABA $\mathrm{A}_{\mathrm{A}}$ receptor subunit $\beta 3$.

Syndromes: ADNFLE, autosomal dominant nocturnal frontal lobe epilepsy; BFNS, benign familial neonatal seizures; GEFS ${ }^{+}$, generalized epilepsy with febrile seizures plus; SMEI, severe myoclonic epilepsy of infancy; CAE, childhood absence epilepsy; FS, febrile seizures; BFNIS, benign familial neonatal-infantile seizures; ADJME, autosomal dominant juvenile myoclonic epilepsy; IGE, idiopathic generalized epilepsy; ADPEAF, autosomal dominant partial epilepsy with auditory features; JME, juvenile myoclonic epilepsy; CPS, complex partial seizures; GCTS, generalized tonic-clonic seizures; TLE, temporal lobe epilepsy. 
tibility genes $C A C N A 1 H, G A B R D, K C N D 2$, and GABRB3 (Table 1).

The scope for ion channel involvement in epilepsy is enormous given the number of neuronal ion channels. ${ }^{8}$ Numerous combinations of defects in neuronally expressed ion channels could, when acting additively, be causative for complex epilepsy. Any genes, including ion channels, suspected of having susceptibility alleles on the basis of statistical association studies alone remain speculative in the absence of expression studies tying mutations (for monogenic epilepsies) or variants (for complex epilepsies) to functional effects consistent with a mechanism for hyperexcitability leading to epilepsy. However, statistical association studies remain the most likely approach for the identification of any common susceptibility genes that are not ion channels. These will perhaps provide an avenue of escape from potential bias toward ion channels resulting from prior knowledge of the gene families involved in the monogenic epilepsies.

\section{ACETYLCHOLINE RECEPTORS}

\section{CHRNA4, CHRNB2, and CHRNA2}

Mutations of the nicotinic acetylcholine receptor (AChR) subunits are associated with autosomal dominant nocturnal frontal lobe epilepsy (ADNFLE), but only $12 \%$ of ADNFLE patients have mutations in AChR subunits. ${ }^{9}$ This rare epilepsy syndrome is characterized by partial seizures, originating from the frontal lobe, which occur during light sleep. ${ }^{10}$ The majority of the mutations which have been described in this disorder are seen in the genes CHRNA4 with four different mutations, some of which are recurrent and one of which has been observed as a de novo mutation, and CHRNB2 with three different mutations, one being associated with distinct memory deficits as well as ADNFLE. ${ }^{9}{ }^{11}$ A single family with a mutation in the gene CHRNA2 has also been described. ${ }^{12}$ All of these mutations alter amino acids in the transmembrane domains of the AChR proteins.

The neuronal nicotinic AChR is a pentameric complex consisting of three alpha and two beta subunits, with the most common receptor in the brain being made up of the $\alpha 4$ and $\beta 2$ subunits. A study of five of the ADNFLE-associated mutations in these subunits shows that they all reduce the calcium dependence of the acetylcholine response. This has the potential to enhance excitatory neurotransmitter release during sleep, triggering seizures. ${ }^{13}$ The single known mutation in the $\alpha 2$ subunit increases sensitivity to acetylcholine, a functional effect consistent with increased seizure susceptibility. ${ }^{12}$

\section{POTASSIUM CHANNELS}

\section{KCNQ2 and $K C N Q 3$}

Mutations in the voltage-gated potassium channel subunit genes $K C N Q 2$ and $K C N Q 3$ are associated with the autosomal dominant epilepsy syndrome benign familial neonatal seizures (BFNS), which was originally described by Rett and Teubel ${ }^{14}$ in 1964 . BFNS usually occurs in the first few days of life, presenting as seizures in a previously well neonate. Spontaneous remission of seizures usually occurs by one month of age; however, later remission has been reported in some cases and approximately $15 \%$ of patients have occasional seizures later in life. Mutations of $K C N Q 2$ and $K C N Q 3$ were first reported in BFNS families in 1998. ${ }^{15-17}$ Since then, more than 50 mutations of $K C N Q 2$ have been described in BFNS families ${ }^{18-30}$ and de novo mutations have been reported in patients with benign idiopathic neonatal seizures. $^{21}$ These mutations are spread throughout the gene, and include missense, frameshift, truncation, and splice site mutations, as well as a deletion of multiple exons. Various other neurological phenotypes, including myokymia ${ }^{31}$ epileptic encephalopathy, ${ }^{20}$ and benign epilepsy with centrotemporal spikes, ${ }^{30}$ have been observed in some BFNS families where the association with $K C N Q 2$ mutations is presumed to be causal. Mutations of $K C N Q 3$ in BFNS are rare, with only four described. ${ }^{19,32}$ All of these are missense mutations that alter amino acids in the pore-loop of the $K C N Q 3$ protein.

A KCNQ potassium channel consists of four subunits as well as accessory proteins. ${ }^{33-35}$ The KCNQ subunits contain three domains: a small N-terminal domain; the transmembrane domain made up of six transmembrane segments (S1-S6); and the large C-terminal domain, which is involved in interaction with the other subunits of the channel as well as accessory proteins. The pore loop between transmembrane segments S5 and S6 forms the lining of the ion pore. The KCNQ2 and KCNQ3 subunits form the M-channel, which carries the muscarinic-regulated potassium current, or M-current. This current is a negative regulator of neuronal excitability and thus its reduction would be expected to lead to neuronal hyperexcitability. A study by Schroeder et al. ${ }^{36}$ showed that pore mutations in both KCNQ2 and KCNQ3 reduce the potassium current by $30 \%$ to $60 \%$, confirming this action. Haploinsufficiency has also been suggested as a mechanism for the reduction of the potassium current. ${ }^{15,37}$ This is likely to be the mechanism by which some of the frameshift and truncation mutations have their effect, as transcripts containing premature stop codons could be subject to nonsense-mediated decay and therefore not translated. ${ }^{38}$ Alteration of the functions of the C-terminal domain can also reduce the potassium current. The C-terminal domain interacts with calmodulin and this interaction is necessary for normal channel 
function. $^{34,35}$ Certain BFNS mutations have been shown to affect this interaction. ${ }^{18}$

The mechanism causing the limited age range of seizure occurrence in BFNS is not clearly understood. It is possible that the brain is particularly sensitive to the development of seizures during the neonatal period and that, after this time, the reduction in potassium current resulting from the mutations no longer causes seizures. Alternatively, changes in the expression of ion channels during development may play a role in the onset and offset of seizures in BFNS.

\section{SODIUM CHANNELS}

Voltage-gated sodium channels consist of three subunits. The large alpha subunit contains the ion pore and two small accessory beta subunits modulate channel kinetics. The alpha subunit contains four homologous transmembrane domains (DI-DIV), each containing six transmembrane segments (S1-S6), surrounding the central pore. The transmembrane domains are linked by cytoplasmic loops. Each transmembrane domain contains a pore-loop (P-loop) between S5 and S6, which together form the lining of the ion pore. ${ }^{39}$ Mutations in three voltage-gated sodium channel subunit genes are associated with epilepsy: the alpha subunit genes $S C N 1 A$ and $S C N 2 A$ and the beta subunit gene $S C N 1 B$.

\section{SCN1B}

$S C N 1 B$ was the first sodium channel and fourth ion channel gene implicated in idiopathic epilepsy and established the likelihood of an ongoing series of channelopathies associated with idiopathic epilepsies. ${ }^{40}$ The original mutation has subsequently been found in three additional families, with evidence of a founder mutation. ${ }^{41}$ These families, together with three novel mutations, ${ }^{41,} 42$ have firmly established the relationship between $S C N 1 B$ and $\mathrm{GEFS}^{+}$as well as extending the phenotype to include temporal lobe epilepsy in some families. All $S C N 1 B$ mutations so far described affect the extracellular immunoglobulin-like fold of the protein. Functional studies are contradictory and their interpretation against proposed excitatory mechanisms is complex $^{41}$; however, so far the general effects of $S C N 1 B$ mutations are relaxation of control over alpha subunits and cell adhesion, equating to loss of function.

\section{SCN1A}

Mutations in SCN1A result in a bimodal distribution of phenotypic severity. ${ }^{43,44}$ Missense mutations of relatively mild effect are seen in $\mathrm{GEFS}^{+}$families with a range of associated phenotypes including febrile seizures (FS), ${ }^{45}$ and one family with FS alone. ${ }^{46}$ Because FS is part of the clinical spectrum of GEFS ${ }^{+},{ }^{47}$ we suggest that this family could be another, milder case of $\mathrm{GEFS}^{+}$or by chance alone does not display any other $\mathrm{GEFS}^{+}$phenotypes.

The vast majority of the SCN1A mutations that have been reported are associated with the severe epileptic encephalopathies. These include severe myoclonic epilepsy of infancy (SMEI), borderline SMEI, intractable childhood epilepsy with generalized tonic-clonic seizures and, in one case, infantile spasms. The mutations associated with these disorders are familial $\mathrm{GEFS}^{+}$mutations in about $5 \%$ of cases, but generally arise de novo; that is, they are not present in the parents of the affected child $^{45}$ except in cases of gonadal or somatic mosaicism. ${ }^{48-51}$

The majority of the mutations seen in SMEI are splice site, frameshift, or nonsense mutations. There are also some missense mutations, many of which affect amino acids in the pore loops of the protein. Several exonic deletions and deletions covering the whole SCNIA gene have also been reported in the severe encephalopathies. ${ }^{52-54}$ The larger deletions remove numbers of adjacent genes, sometimes with additional consequences beyond what would be expected had only SCN1A been deleted. ${ }^{55}$

Despite the characterization of more than 100 SCN1A mutations, there is no consistent association between the mutation (change to channel properties) and phenotype. The majority of mutations found in new patients are novel, indicating that much of the pathogenic variation in SCN1A remains to be discovered with scope for continued functional heterogeneity. Of the few mutations so far biophysically examined in vitro, both loss and gain of function have been noted. ${ }^{45}$

While $\mathrm{GEFS}^{+}$fits the strict definition of idiopathic, SMEI and the other severe epileptic encephalopathies were once thought of as "symptomatic" because of associated intellectual and developmental delay with additional neurological signs. They are now known to have a genetic cause. They are all part of the $\mathrm{GEFS}^{+}$spectrum and are usually due to a sodium channelopathy. Indeed, SMEI and borderline SMEI now include a proportion of cases that had previously been misdiagnosed as vaccine encephalopathy. ${ }^{56}$

Electrophysiologic studies of sodium channels have proven to be sensitive to the expression system chosen for the analysis. SCNIA mutations in GEFS ${ }^{+}$and SMEI lead to loss or gain of function, and sometimes complete loss of function depending on the mutation tested. ${ }^{45}$ Such variation remains to be resolved in a channel that presents substantial technical challenges in the laboratory.

Novel insights have recently emerged from an SCN1A knockout mouse where the heterozygote has an SMEI phenotype. Loss of function is seen in the GABAergic interneurons but varies according to the murine strain in which the knockout occurs. This suggests that the mouse genetic background confers protective effects or con- 
versely may lower seizure threshold, influencing the epileptic phenotype. ${ }^{57}$

\section{SCN2A}

Benign familial neonatal-infantile seizures (BFNIS) was described in 1983 by Kaplan and Lacey ${ }^{58}$ Missense mutations of $S C N 2 A$ have been described in eight families with the BFNIS phenotype. ${ }^{59,60}$ A family with benign familial infantile seizures has also been shown to have an SCN2A mutation. ${ }^{61}$ It is probable that some genetic overlap will be seen between families diagnosed as BFNIS and those diagnosed as benign familial infantile seizures because individuals with neonatal onset are not seen in all families. All of the BFNIS mutations identified in SCN2A are missense mutations and they are spread throughout the gene. One mutation was observed in three apparently unrelated families. ${ }^{60}$ The functional effects of four BFNIS mutations have been examined. There is heterogeneity in the way ion channel properties are modified, but all modifications lead to gain of function and increased $\mathrm{Na}^{+}$current, consistent with neuronal excitability. ${ }^{62}$

A mutation of $S C N 2 A$ has been described in a single family in which the proband developed complex partial seizures after an initial diagnosis of febrile seizures plus. ${ }^{63}$ However, there is bilineal inheritance of epilepsy phenotypes in this family, so it is possible that there are additional genes contributing to the phenotype in this case.

\section{GABA RECEPTORS AND CHLORIDE CHANNELS}

\section{GABRG2, GABRA1, and CLCN2}

The $\mathrm{GABA}_{\mathrm{A}}$ receptor is the primary mediator of synaptic inhibition and mutations in the subunits encoded by GABRG2 and GABRAl have been associated with IGE and GEFS ${ }^{+} .{ }^{64-69}$ A report by Audenaert et al. ${ }^{68}$ proposed a novel $G A B R G 2$ mutation as a FS locus; however, the family was of insufficient size to rule out $\mathrm{GEFS}^{+}$, another possible diagnosis because FS is a prominent part of the $\mathrm{GEFS}^{+}$spectrum. ${ }^{47}$ The GABRAl gene was originally implicated in familial juvenile myoclonic epilepsy, ${ }^{66}$ until a de novo GABRAl mutation presented with childhood absence epilepsy (CAE),${ }^{69}$ demonstrating a role for shared genetic determinants among IGE subtypes. The rarity of involvement of each genetic determinant in any particular syndrome is emphasized by the fact that this is based on only one juvenile myoclonic epilepsy family and one CAE patient.

CLCN2 is another chloride ion channel and was originally postulated as a susceptibility locus by virtue of the procedure used to identify a candidate region from analysis in multiplex families; however, clear vertical transmission of phenotypes with associated mutations is seen in multiplex families, consistent with the pattern observed for monogenic disease mutations. ${ }^{70}$ However, the distinction between monogenic epilepsies with single mutations of large effect and complex epilepsies is blurred (FIG. 1). Whether an allele is independently penetrant or expressed only in concert with variants at other loci may depend on the genetic background.

\section{EPILEPSY GENES ASSOCIATED WITH ION CHANNELS}

\section{LGII}

LGII has the distinction of being the first non-ion channel gene associated with idiopathic monogenic epilepsy. ${ }^{71}$ Mutations in LGII are the major cause of autosomal dominant partial epilepsy with auditory features (ADPEAF), and a de novo mutation has also been observed in one sporadic patient with this phenotype. ${ }^{72}$ Genes that are associated with or interact with ion channels are plausible additional candidates for epilepsy and contributors to the channelopathy load. LGII has now been established as a subunit of presynaptic voltagegated $\mathrm{K}_{\mathrm{v}} 1$ channel complexes with a role in the prevention of rapid inactivation of the channel. This function is lost in the presence of $L G I 1$ mutations. ${ }^{73}$ However, not all ADPEAF have detectable LGII mutations, suggesting that there is genetic heterogeneity in this disorder.

\section{EFHC1}

EFHCl was implicated as another non-ion channel gene for idiopathic epilepsy, ${ }^{74,75}$ but it may be ion channel related. $E F H C l$ was reported to increase R-type $\mathrm{Ca}^{2+}$ currents, which were abnormally affected by EFHC1 mutations. The mystery remains of why mutations have only been detected in a proportion of families. The remaining families map to the same location as EFHCl and perhaps have mutations in a closely linked and yet unidentified gene or there are noncoding $E F H C l$ mutations, which have not been identified, in these families. No association was detected with single nucleotide polymorphisms within the promoter region of the gene. ${ }^{74}$

\section{IDIOPATHIC EPILEPSY ASSOCIATED WITH OTHER PAROXYSMAL DISORDERS}

Epilepsy has been reported cosegregating with hemiplegic migraine or episodic ataxia in occasional families. Mutations in the calcium channel subunit gene CACNAIA are associated with familial hemiplegic migraine (FHM), episodic ataxia type 2, and spinocerebellar ataxia type 6. A single family with a CACNA1A mutation has been reported in which the phenotypes include epilepsy. ${ }^{76}$ Similarly, mutations of the cation ATPase pump gene ATP1A2 are usually associated with FHM, but a family in which BFIS partially segregates 
with the ATP1A2 mutation has been reported. ${ }^{77}$ Conversely, an SCN1A mutation usually associated with epilepsy, has been reported in an FHM family. ${ }^{78}$

\section{MONOGENIC TO COMPLEX CHANNELOPATHIES}

While rare families with epilepsy segregate a mutation of major effect in a Mendelian pattern, epilepsy is most commonly seen in sporadic cases or within small family clusters. This is consistent with a model of complex genetics in which a combination of susceptibility alleles is inherited, resulting in the manifestation of the epilepsy phenotype. Contributing susceptibility alleles are predicted to be variants of minor functional effect which are present at low frequencies in the general population.

Speculations on the genetic architecture of the susceptibility alleles underlying the common multifactorial epilepsies have recently been reviewed. ${ }^{6,79,80}$ Minimal data come, so far, from three susceptibility genes, CACNAIH, $G A B R D$, and $K C N D 2$, detected by the candidate gene approach, and GABRB 3 detected by association analysis followed by functional confirmation. None of these are common susceptibility loci, except by definition GABRB3. CACNA1H, GABRD, and KCND2 are consistent with the polygenic heterogeneity model involving, for any given individual, a subset of rare variants (frequency less than 1\%) and low frequency polymorphisms drawn from a large, genetically heterogeneous pool of susceptibility alleles segregating in the normal population. ${ }^{6}$ Under this model, response to AEDs is not uniform for the same seizure phenotypes. Nor will such a model allow complete dissection of the genetic architecture of complex epilepsy by statistical association analysis. There is an unknown number of common susceptibility genes that may be detectable by association analysis. Tan et al. ${ }^{79,81}$ have reviewed in detail the results and methodologies for the application of association studies to complex epilepsy with a view to maximizing information provided by such studies.

\section{CACNA1H}

Variants in the T-type calcium channel gene CACNAIH were initially associated with $\mathrm{CAE}^{82}$ but have since been described in other epilepsy phenotypes. ${ }^{83}$ These variants generally alter conserved amino acids but do not segregate with affection status in families. Electrophysiologic studies showed that at least some of the variants affect protein function and these are likely to be susceptibility alleles. ${ }^{84-87}$ Analysis of a polymorphism, R788C, also showed that it alters protein function in a manner consistent with it being a common susceptibility allele. ${ }^{86}$ These studies show that variation in CACNAIH contributes to the pathogenesis of complex epilepsy, but no variants have been described that are sufficient to cause epilepsy on their own. A detailed review of calcium channels and IGEs is given by Khosravani and Zamponi. ${ }^{88}$

\section{GABRD}

As discussed above, the $\mathrm{GABA}_{\mathrm{A}}$ receptor subunits encoded by $G A B R G 2$ and GABRA1 are associated with monogenic forms of IGE and $\mathrm{GEFS}^{+}$in rare families. $\mathrm{GABA}_{\mathrm{A}}$ receptors in vivo have been shown to have the subunit stoichiometry $2 \alpha 2 \beta$ and $1 \gamma$ or $1 \delta$. A rare variant and a low frequency polymorphism in $G A B R D$, which encodes the $\delta$ subunit, have properties consistent with being susceptibility alleles for complex IGE. Expression of the GABRD variant E177A and the polymorphism $\mathrm{R} 220 \mathrm{H}$ in human embryonic kidney cells results in reduced $\mathrm{GABA}_{\mathrm{A}}$ receptor current amplitude in comparison with the common GABRD allele. ${ }^{89}$ The reduced GABAinduced currents most likely result from the decreased surface expression and shorter duration of channel opening of receptors containing E177A or R220H substitutions. ${ }^{90} \delta$-containing $\mathrm{GABA}_{\mathrm{A}}$ receptors mediate tonic inhibition, suggesting this mechanism plays a role in epilepsy. The size and duration of excitatory synaptic activities is reduced by the action of tonic inhibition, making the firing of action potentials less likely. ${ }^{91}$ Predicted disruption of tonic inhibition in individuals carrying the GABRD variants is therefore consistent with neuronal hyperexcitability and increased epilepsy susceptibility.

These results suggest that while $G A B R D$ is a susceptibility gene for complex epilepsies it is rarely implicated as a susceptibility component, as predicted by the polygenic heterogeneity model. ${ }^{80}$ The rare GABRD E177A variant was present in one small $\mathrm{GEFS}^{+}$family and the $\mathrm{R} 220 \mathrm{H}$ polymorphism was present at a similar frequency in patients and controls in two populations. ${ }^{89,92}$ Neither variant was found to segregate with epilepsy in a large family, consistent with a role as a gene of small effect lowering the seizure threshold in sporadic cases or small families with complex epilepsy.

\section{KCND2}

Singh et al. ${ }^{93}$ characterized a rare mutation of $K C N D 2$ in a patient with temporal lobe epilepsy (TLE). TLE is a complex epilepsy, apart from rare families of ADPEAF associated with LGII mutations. The mutation truncated the protein leading to attenuated density of $\mathrm{K}^{+}$current density consistent with neuronal excitability. The mutation was transmitted from the asymptomatic father without extended family analysis; hence, on the available evidence, it represents a susceptibility allele for complex TLE rather than a gene for monogenic epilepsy.

\section{GABRB3}

The dampening of GABRB3 transcriptional activity associated with a specific promoter haplotype identifies 
the fourth functionally characterized susceptibility gene for complex epilepsy. ${ }^{94}$ Successful replication of the initial statistical association study in CAE was followed by functional validation. GABRB3 and $C A C N A I H$ may represent the beginning of an ascertainment of a complementary polygenic set of susceptibility genes for CAE. With the functional validation of four susceptibility genes, CACNAIH, GABRD, GABRB3, and KCND2, within a decade of the realization that monogenic epilepsies were a family of channelopathies ${ }^{40}$ the same pattern is now clearly emerging for the complex epilepsies. The next quantum leap in the understanding of the genetic architecture of complex epilepsies could come with the functional characterization of all the variants being described from large scale ion channel resequencing projects underway in several centers.

\section{GENETIC AND PHENOTYPIC HETEROGENEITY}

A feature of monogenic epilepsy is considerable genetic heterogeneity. In a polygenic model, genetic heterogeneity would effectively be multiplied. In monogenic epilepsy CHRNA4, CHRNB2 and CHRNA2 mutations can all lead to ADNFLE, ${ }^{12,95,96}$ and SCNIB, SCNIA, $S C N 2 A$, and GABRG2 mutations can all lead to $\mathrm{GEFS}^{+}{ }^{40,43,64,65}$ Extrapolated to complex polygenic epilepsies this underlying genetic complexity would be multiplied for particular syndromes of IGE.

Variable expressivity of mutations in $S C N 1 A,{ }^{43,44,97}$ $S C N 2 A,,^{59,63}$ and $G A B R G 2^{64,65}$ can lead to a range of syndromes. The same mutations in $S C N 1 A,{ }^{98} S C N 1 B,{ }^{99}$ and $G A B R G 2,{ }^{100}$ perhaps modulated by modifiers which underlie variable expressivity, can lead to different epilepsy syndromes. The GEFS ${ }^{+}$spectrum shows the extreme seizure heterogeneity that can be associated with the same mutation in the same family. Extrapolated to complex epilepsies, the phenotypic overlap for the underlying genetic determinants may be multiplied as the number of susceptibility genes underlying the complex syndrome increases. The same clinical phenotype defining a specific syndrome or subsyndrome of complex epilepsy may have underlying genetic complexity multiplied well beyond the genetic heterogeneity already recognized for some of the monogenic epilepsies.

\section{THERAPEUTICS}

The practice of therapeutics in epilepsy is currently based on clinical rather than molecular determinants. Epilepsy syndrome classification, delineated by electroclinical features, provides the clinician with a structured approach to diagnosis and management of patients with epilepsy. A specific syndrome diagnosis is associated with a therapeutic regimen that has evolved from the results of drug trials and clinical experience.

Current AEDs prevent seizures by dampening neuronal excitation via ion channel mechanisms. Ion channel mutations promote excitation through a number of mechanisms that include changes to gating, time to channel inactivation and recovery from inactivation, distribution and density of receptors, and retention of receptors within the endoplasmic reticulum. Most medications are thought to target sodium and calcium ion channels or GABA and glutamate receptors. ${ }^{101-103}$

The $30 \%$ of nonresponsive cases, ${ }^{104}$ as well as cases where seizure control is achieved but with significant side effects, lend themselves to the trial and error application of the more recent AEDs. ${ }^{105}$ They all have side effects, may entail lifelong treatment, and require lifestyle adjustments where necessary.

Sodium valproate is the first choice for generalized epilepsy and carbamazepine for partial epilepsies ${ }^{105}$ but treatment choices are tailored to each patient's individual circumstances. More detailed reviews of the management of therapeutic interventions in IGEs are given by Benbadis ${ }^{106}$ and Camfield and Camfield. ${ }^{107}$ Special considerations exist for the treatment of SMEI and related encephalopathies where some AEDs are effective ${ }^{108}$ and others worsen the seizures. ${ }^{109}$

Resistance to AEDs in the nonresponders is a major unsolved issue. ${ }^{110}$ One hypothesis that is amenable to pharmacogenetic investigations is of genetic variation related to drug transport and metabolism, with potentially efficacious therapeutic agents not reaching their target. Alternatively, genetic variation in the ion channels themselves may alter the effect of AEDs. Additionally, the $30 \%$ of nonresponders may have epilepsy syndromes that are fundamentally resistant to current therapies, and new targets need to be explored. The pharmacogenetics of adverse drug reactions is rapidly becoming an area of importance in epilepsy genetics. ${ }^{11}$

The molecular basis of most idiopathic epilepsies with a polygenic basis is unknown, with only limited insights into susceptibility alleles emerging at present. Even though in vivo and in vitro functional studies shed light on mechanisms underlying seizure disorders, these remain at a basic level and often show conflicting results. The model systems used are often far more simplistic than a complex system such as man, and hence their findings do not currently inform treatment decisions.

Many antiepileptic drugs are known to work on ion channels, including a number with sodium channel or GABA receptor actions. Simplistically, it would seem intuitive to use an agent with a sodium channel mechanism of action such as carbamazepine or lamotrigine for a sodium channelopathy. However, the outcome is not straightforward. For example, SMEI, with an SCN1A mutation, may be exacerbated by lamotrigine, ${ }^{109}$ while 
$\mathrm{GEFS}^{+}$phenotypes, with an SCN1A mutation, may respond well to lamotrigine. Thus, our current molecular findings do not guide treatment choices now but rather in the future with improved understanding of the neurobiology, it may be possible to apply molecular findings to assist optimization of treatment regimes. The major problem with current AEDs is the lack of ion channel selectivity.

\section{CONCLUSION}

The channelopathy concept for the idiopathic epilepsies has become firmly established over the past decade primarily by successful gene hunting for the monogenic epilepsies in large families. Most AEDs currently in use target ion channels and receptors so their success in the treatment of epilepsy now makes sense. The same treatment principles will apply to the complex epilepsies, but there may be a polygenic mixture of ion channel susceptibility alleles with the addition of perhaps other families of susceptibility genes making response to any specific AED less predictable. Establishing AED regimens tailored to molecular defects requires genetically homogeneous test populations of either monogenic or complex epilepsies. Further inroads into solving the genetics of complex epilepsies are the initial step along the path to optimizing epilepsy treatment. However, the task of solving the genetics of the complex epilepsies remains formidable. Association studies have not yielded significant results as yet and ultimately the only solution may be large scale functional analysis of candidate genes.

Acknowledgments: This work was supported by the National Health and Medical Research Council of Australia.

\section{REFERENCES}

1. Sander JW. The epidemiology of epilepsy revisted. Curr Opin Neurol 2003;16:165-170.

2. Annegers JF. The epidemiology of epilepsy. In: The treatment of epilepsy: principles and practice. Elaine Wylie, MD, ed. Baltimore: Williams and Wilkins; 1996.

3. Berkovic SF, Howell RA, Hay DA, Hopper JL. Epilepsies in twins: genetics of the major epilepsy syndromes. Ann Neurol 1998;43:435-445.

4. Gardiner M. Genetics of idiopathic generalized epilepsies. Epilepsia 2005;46(suppl 9):15-20.

5. Turnbull J, Lohi H, Kearney JA, et al. Sacred disease secrets revealed: the genetics of human epilepsy. Hum Mol Genet 2005; 14:2491-2500.

6. Mulley JC, Scheffer IE, Harkin LA, Berkovic SF, Dibbens LM. Susceptibility genes for complex epilepsy. Hum Mol Genet 2005; 14:R243-249.

7. Graves TD. Ion channels and epilepsy. QJM 2006;99:201-217.

8. Gargus, J.J. Unraveling monogenic channelopathies and their implications for complex polygenic disease. Am J Hum Genet 2003;72;785-803.

9. Combi R, Dalpra L, Tenchini ML, Ferini-Strambi L. Autosomal dominant nocturnal frontal lobe epilepsy-a critical overview. J Neurol 2004;251:923-934.

10. Scheffer IE, Bhatia KP, Lopes-Cendes I, et al. Autosomal dom- inant nocturnal frontal lobe epilepsy. A distinctive clinical disorder. Brain 1995;118:61-73.

11. Bertrand D, Elmslie F, Hughes E, et al. The CHRNB2 mutation $\mathrm{I} 312 \mathrm{M}$ is associated with epilepsy and distinct memory deficits. Neurobiol Dis 2005;20:799-804.

12. Aridon P, Marini C, Di Resta C, et al. Increased sensitivity of the neuronal nicotinic receptor alpha 2 subunit causes familial epilepsy with nocturnal wandering and ictal fear. Am J Hum Genet 2006;79:342-350.

13. Rodrigues-Pinguet N, Jia L, Li M, et al. Five ADNFLE mutations reduce the $\mathrm{Ca} 2+$ dependence of the mammalian $\alpha 4 \beta 2$ acetylcholine response. J Physiol 2003;550:11-26.

14. Rett A, Teubel R. Neugeborenen krampfe im rahmen einer epileptisch belasten familie. Wien Klin Wochenschr 1964;76:609613.

15. Biervert C, Schroeder BC, Kubisch C, et al A potassium channel mutation in neonatal human epilepsy. Science 1998;279:403406.

16. Charlier C. Singh NA, Ryan SG, et al. A pore mutation in a novel KQT-like potassium channel gene in an idiopathic epilepsy family. Nat Genet 1998;18:53-55.

17. Singh NA, Charlier C, Stauffer D, et al. A novel potassium channel gene, KCNQ2, is mutated in an inherited epilepsy of newborns. Nat Genet 1998;18:25-29.

18. Richards MC, Heron SE, Spendlove HE, et al. Novel mutations in the KCNQ2 gene link epilepsy to a dysfunction of the KCNQ2calmodulin interaction. J Med Genet 2004;41:e35.

19. Singh NA, Westenkow P, Charlier C, et al. KCNQ2 and KCNQ3 potassium channel genes in benign familial neonatal convulsions; expansion of the functional and mutational spectrum. Brain 2003; 126:2726-2737.

20. Borgatti R, Zucca C, Cavallini A, et al. A novel mutation in KCNQ2 associated with BFNC, drug resistant epilepsy and mental retardation. Neurology 2004;63:57-65.

21. Claes LRF, Ceulemans B, Audenaert D, et al. De novo KCNQ2 mutations in patients with benign neonatal seizures. Neurology 2004;63:2155-2158.

22. Pereira S, Roll P, Krizova J, et al. Complete loss of the cytoplasmic carboxyl terminus of the KCNQ2 potassium channel: a novel mutation in a large Czech pedigree with benign familial neonatal convulsions or other epileptic phenotypes. Epilepsia 2004;45: 384-390.

23. Tang B, Li H, Xia K, et al. A novel mutation in KCNQ2 gene causes benign familial neonatal convulsions in a Chinese family. J Neurol Sci 2004;221:31-34.

24. Bassi MT, Balottin U, Panzeri C, et al. Functional analysis of $\mathrm{KCNQ} 2$ and KCNQ3 gene variants found in a large pedigree with benign familial neonatal convulsions. Neurogenetics 2005;6:185193.

25. Pinto D, de Haan GJ, Carton D, et al. Gene symbol: KCNQ2. Disease: benign neonatal familial convulsion. Hum Genet 2005; 117:300.

26. Schmitt B, Wohlrab G, Sander T, Steinlein OK, Hajnal BL. Neonatal seizures with tonic clonic sequences and poor developmental outcome. Epilepsy Res 2005;65:161-168.

27. de Haan GJ, Pinto D, Carton D, et al. A novel splicing mutation in KCNQ2 in a multigenerational family with BFNC followed for 25 years. Epilepsia 2006;47:851-859.

28. Hunter J, Maljevic S, Shankar A, et al. Subthreshold changes of voltage-dependent activation of the Kv7.2 channel in neonatal epilepsy. Neurobiol Dis 2006;24:194-201.

29. Zhou X, Ma A, Liu X, et al. Infantile seizures and other epileptic phenotypes in Chinese family with a missense mutation of KCNQ2. Eur J Pediatr 2006;165:691-695.

30. Zimprich F, Ronen GM, Stögmann W, et al. Andreas Rett and benign familial neonatal convulsions revisited. Neurology 2006; 67:864-866.

31. Dedek K, Kunath B, Kananura C, Reuner U, Jentsch TJ, Steinlein OK. Myokymia and neonatal epilepsy caused by a mutation in the voltage sensor of the KCNQ2 K+ channel. Proc Natl Acad Sci U S A 2001;98:12272-12277.

32. Li HY, Tang BS, Yan XX, et al. Clinical and mutational analysis of KCNQ3 gene in a Chinese family with benign familial neo- 
natal convulsions. Zhonghua Yi Xue Yi Chuan Xue Za Zhi 2006;23:374-377.

33. Schwake M, Jentsch TJ, Friedrich T. A carboxy-terminal domain determines the subunit specificity of KCNQ K+ channel assembly. EMBO Rep 2003;4:76-81.

34. Wen H, Levitan IB. Calmodulin is an auxiliary subunit of KCNQ2/3 potassium channels. J Neurosci 2002;22:7991-8001.

35. Yus-Najera E, Santana-Castro I, Villaroel A. The identification and characterization of a non-continuous calmodulin binding site in non-inactivating voltage-dependent KCNQ potassium channels. J Biol Chem 2002;277:28545-28553.

36. Schroeder BC, Kubisch C, Stein V, Jentsch TJ. Moderate loss of function of cyclic-AMP-modulated KCNQ2/KCNQ3 K+ channel causes epilepsy. Nature 1998;396:687-690.

37. Lerche H, Biervert C, Alekov AK, et al. A reduced $\mathrm{K}+$ current due to a novel mutation in KCNQ2 causes neonatal convulsions. Ann Neurol 1999;46:305-312.

38. Maquat LE. Nonsense-mediated mRNA decay in mammals. J Cell Sci 2005;118:1773-1776.

39. Catterall WA. A 3D view of sodium channels. Nature 2001;409: 988-991.

40. Wallace RH, Wang DW, Singh R, et al. Febrile seizures and generalized epilepsy associated with a mutation in the $\mathrm{Na}+$ channel $\beta 1$ subunit gene SCN1B. Nat Genet 1998;19:366-370.

41. Scheffer IE, Harkin LA, Grinton BE, et al. Temporal lobe epilepsy and GEFS + phenotypes associated with SCN1B mutations. Brain 2007;130:100-109.

42. Audenaert D, Claes L, Ceulemans, Lofgren A, Van Broekhoven C, De Jonge P. A deletion in SCN1B is associated with febrile seizures and early-onset absence epilepsy. Neurology 2003;61: $854-856$.

43. Escayg A, MacDonald BT, Meisler MH, et al. Mutations of SCN1A, encoding a neuronal sodium channel, in two families with GEFS +2. Nat Genet 2000;24:343-345.

44. Claes L, Del-Favero J, Ceulemans B, Lagae L, Van Broeckhoven $\mathrm{C}$, De Jonghe P. De novo mutations in the sodium-channel gene SCN1A cause severe myoclonic epilepsy of infancy. Am J Hum Genet 2001;68:1327-1332.

45. Mulley JC, Scheffer IE, Petrou S, Dibbens LM, Berkovic SF, Harkin LA. SCN1A mutations and epilepsy. Hum Mutat 2005; 25:535-542.

46. Mantegazza M, Gambardella A, Rusconi R, et al. Identification of an Nav1.1 sodium channel (SCN1A) loss-of-function mutation associated with familial simple febrile seizures. Proc Natl Acad Sci U S A 2005;102:18177-18182.

47. Scheffer IE, Berkovic SF. Generalized epilepsy with febrile seizures plus. A genetic disorder with heterogeneous clinical phenotypes. Brain 1997;120:479-490.

48. Depienne C, Arzimanoglou A, Trouillard O, et al. Parental mosaicism can cause recurrent transmission of SCN1A mutations associated with severe myoclonic epilepsy of infancy. Hum Mutat 2006;27:389.

49. Gennaro E, Santorelli FM, Bertini E, et al. Somatic and germline mosaicisms in severe myoclonic epilepsy of infancy. Biochem Biophys Res Commun 2006;341:489-493.

50. Marini C, Mei D, Cross JH, Guerrini R. Mosaic SCN1A mutation in familial severe myoclonic epilepsy of infancy. Epilepsia 2006; 47:1737-1740.

51. Morimoto M, Mazaki E, Nishimura A, et al. SCN1A mutation mosaicism in a family with severe myoclonic epilepsy in infancy. Epilepsia 2006;47:1732-1736.

52. Madia F, Striano P, Gennaro E, et al. Cryptic chromosome deletions involving SCN1A in severe myoclonic epilepsy of infancy. Neurology 2006;67:1230-1235.

53. Mulley JC, Nelson P, Guerrero S, et al. A new molecular mechanism for severe myoclonic epilepsy of infancy: exonic deletions in SCN1A. Neurology 2006;67:1094-1095.

54. Suls A, Claeys KG, Goossens D, et al. Microdeletions involving the SCN1A gene may be common in SCN1A-mutation-negative SMEI patients. Hum Mutat 2006;27:914-920.

55. Pereira S, Vieira JP, Barroca F, et al. Severe epilepsy, retardation and dysmorphic features with a $2 \mathrm{q}$ deletion including SCN1A and SCN2A. Neurology 2004;63:191-192.
56. Berkovic SF, Harkin L, McMahon JM, et al. De-novo mutations of the sodium channel gene SCN1A in alleged vaccine encephalopathy: a retrospective study. Lancet Neurol 2006;5:488-492.

57. Yu FH, Mantegazza M, Westenbroek RE, et al. Reduced sodium current in GABAergic interneurons in a mouse model of severe myoclonic epilepsy in infancy. Nat Neurosci 2006;9:1142-1149.

58. Kaplan RE, Lacey DJ. Benign familial neonatal-infantile seizures. Am J Med Genet 1983;16:595-599.

59. Heron SE, Crossland KM, Andermann E, et al. Sodium-channel defects in benign familial neonatal-infantile seizures. Lancet 2002;360:851-852.

60. Berkovic SF, Heron SE, Giordano L, et al. Benign familial neonatal-infantile seizures: characterization of a new sodium channelopathy. Ann Neurol 2004;55:550-557.

61. Striano P, Bordo L, Lispi ML, et al. A novel SCN2A mutation in family with benign familial infantile seizures. Epilepsia 2006;47: $218-220$.

62. Scalmani P, Rusconi R, Armatura E, et al. Effects in neocortical neurons of mutations of the Nav1.2 $\mathrm{Na}+$ channel causing benign familial neonatal-infantile seizures. J Neurosci 2006;26:1010010109.

63. Ito M, Shirasaka Y, Hirose S, Sugawara T, Yamakawa K. Seizure phenotypes of a family with missense mutations in SCN2A. Pediatr Neurol 2004;31:150-152

64. Baulac S, Huberfeld G, Gourfinkel-An I, et al. First genetic evidence of $\mathrm{GABA}(\mathrm{A})$ receptor dysfunction in epilepsy: a mutation in the gamma2-subunit gene. Nat Genet 2001;28:46-48.

65. Wallace RH, Marini C, Petrou S, et al. Mutant GABA(A) receptor gamma2-subunit in childhood absence epilepsy and febrile seizures. Nat Genet 2001;28:49-52.

66. Cossette P, Liu L, Brisebois K, et al. Mutation of GABRA1 in an autosomal dominant form of juvenile myoclonic epilepsy. Nat Genet 2002;31:184-189.

67. Kananura C, Haug K, Sander T, et al. A splice-site mutation in GABRG2 associated with childhood absence epilepsy and febrile convulsions. Arch Neurol. 2002;59:1137-1141.

68. Audenaert D, Schwartz E, Claeys KG, et al. A novel GABRG2 mutation associated with febrile seizures. Neurology 2006;67: 687-690.

69. Maljevic S, Krampfl K, Cobilanschi J, et al. A mutation in the GABAA receptor $\alpha 1$-subunit is associated with absence epilepsy. Ann Neurol 2006;59:983-987.

70. Haug K, Warnstedt M, Alekov AK, et al. Mutations in CLCN2 encoding a voltage-gated chloride channel are associated with idiopathic generalized epilepsies. Nat Genet 2003;33:527-532.

71. Kalachikov S, Evgrafov O, Ross B, et al. Mutations in LGI1 cause autosomal-dominant partial epilepsy with auditory features. Nat Genet 2002;30:335-341.

72. Bisulli F, Tinuper P, Scudellaro E, et al. A de novo LGI1 mutation in sporadic partial epilepsy with auditory features. Ann Neurol. 2004;56:455-456.

73. Schulte U, Thumfart JO, Klocker N, et al. The epilepsy-linked Lgi1 protein assembles into presynaptic Kv1 channels and inhibits inactivation by $\operatorname{Kv} \beta 1$. Neuron 2006;49:697-706.

74. Suzuki T, Delgado-Escueta AV, Aguan K, et al. Mutations in EFHC1 cause juvenile myoclonic epilepsy. Nat Genet 2004;36: 842-849.

75. Ma S, Blair MA, Abou-Khalil B, Lagrange AH, Gurnett CA, Hedera P. Mutations in the GABRA1 and EFHC1 genes are rare in familial juvenile myoclonic epilepsy. Epilepsy Res 2006;71: 129-134.

76. Kors EE, Melberg A, Vanmolkot KR, et al. Childhood epilepsy, familial hemiplegic migraine, cerebellar ataxia, and a new CACNA1A mutation. Neurology 2004;63:1136-1137.

77. Vanmolkot KR, Kors EE, Hottenga JJ, et al. Novel mutations in the $\mathrm{Na}+, \mathrm{K}+$-ATPase pump gene ATP1A2 associated with familial hemiplegic migraine and benign familial infantile convulsions. Ann Neurol 2003;54:360-366.

78. Dichgans M, Freilinger T, Eckstein G, et al. Mutation in the neuronal voltage-gated sodium channel SCN1A in familial hemiplegic migraine. Lancet 2005;366:371-377.

79. Tan NCK, Mulley JC, Scheffer IE. Genetic dissection of the common epilepsies. Curr Opin Neurol 2006;19:157-163. 
80. Dibbens LM, Heron SE, Mulley JC. A polygenic heterogeneity model for complex epilepsy? Genes Brain Behav 2007 (in press).

81. Tan NCK, Mulley JC, Berkovic SF. Genetic association studies in epilepsy: "the truth is out there". Epilepsia 2004;45:1429-1442.

82. Chen Y, Lu J, Pan H, et al. Association between genetic variation of CACNA1H and childhood absence epilepsy. Ann Neurol 2003;54:239-243.

83. Heron SE, Phillips HA, Mulley JC, et al. Genetic variation of CACNA1H in idiopathic generalized epilepsy. Ann Neurol 2004; 55:595-596.

84. Khosravani H, Altier C, Simms B, et al. Gating effects of mutations in the Cav3.2 T-type calcium channel associated with childhood absence epilepsy. J Biol Chem 2004;279:9681-9684.

85. Khosravani H, Bladen C, Parker DB, et al. Effects of Cav3.2 channel mutations linked to idiopathic generalized epilepsy. Ann Neurol 2005;57:745-749.

86. Vitko I, Chen Y, Arias JM, Shen Y, Wu XR, Perez-Reyes E. Functional characterization and neuronal modeling of the effects of childhood absence epilepsy variants of CACNA1H, a T-type calcium channel. J Neurosci 2005;25:4844-4855.

87. Peloquin JB, Khosravani H, Barr W, et al. Functional analysis of Cav3.2 T-type calcium channel mutations linked to childhood absence epilepsy. Epilepsia 2006;47:655-658.

88. Khosravani H, Zamponi GW. Voltage-gated calcium channels and idiopathic generalized epilepsies. Physiol Rev 2006;86:941966.

89. Dibbens LM, Feng HJ, Richards MC, et al. GABRD encoding a protein for extra- or peri-synaptic GABAA receptors is a susceptibility locus for generalized epilepsies. Hum Mol Genet 2004; 13:1315-1319.

90. Feng HJ, Kang JQ, Song L, Dibbens L, Mulley J, Macdonald RL. $\delta$ subunit susceptibility variants E177A and R220H associated with complex epilepsy alter channel gating and surface expression of $\alpha 4 \beta 2 \delta \mathrm{GABA}_{\mathrm{A}}$ receptors. J Neurosci 2006;26:14991506.

91. Farrant M, Nusser Z. Variations on an inhibitory theme: phasic and tonic activation of GABAA receptors. Nat Rev Neurosci 2005;6:215-229.

92. Lenzen KP, Heils A, Lorenz S, Hempelmann A, Sander T. Association analysis of the Arg220His variation of the human gene encoding the GABA $\delta$ subunit with idiopathic generalized epilepsy. Epilepsy Res 2005;65:53-57.

93. Singh B, Ogiwara I, Kaneda M, et al. A Kv4.2 truncation mutation in a patient with temporal lobe epilepsy. Neurobiol Dis 2006;24:245-253.

94. Urak L, Feucht M, Fathi N, Hornik K, Fuchs K. A GABRB3 promoter haplotype associated with childhood absence epilepsy impairs transcriptional activity. Hum Mol Genet 2006;15:25332541.

95. Steinlein OK, Mulley JC, Propping P, et al. A missense mutation in the neuronal nicotinic acetylcholine receptor $\alpha 4$ subunit is associated with autosomal dominant nocturnal frontal lobe epilepsy. Nat Genet 1995;11:201-203.

96. Phillips HA, Favre I, Kirkpatrick M, et al. CHRNB2 is the second acetylcholine receptor subunit associated with autosomal dominant nocturnal frontal lobe epilepsy. Am J Hum Genet 2001;68: 225-231.

97. Wallace RH, Hodgson BL, Grinton BE, et al. Sodium channel $\alpha 1$-subunit mutations in severe myoclonic epilepsy of infancy and infantile spasms. Neurology 2003;61:765-769.

98. Nabbout R, Gennaro E, Dalla Bernardina B, et al. Spectrum of SCN1A mutations in severe myoclonic epilepsy of infancy. Neurology 2003;60:1961-1967.

99. Wallace RH, Scheffer IE, Parasivam G, et al. Generalized epilepsy with febrile seizures plus: mutation of the sodium channel subunit SCN1B. Neurology 2002;58:1426-1429.

100. Harkin LA, Bowser DN, Dibbens LM, et al. Truncation of the GABAA-receptor $\gamma 2$ subunit in a family with generalized epilepsy with febrile seizures plus. Am J Hum Genet 2002;70:530536.

101. Loscher W. Current status and future directions in the pharmacotherapy of epilepsy. Trends Pharmacol Sci 2002;23:113-118.

102. Rogawski MA, Loscher W. The neurobiology of antiepileptic drugs. Nat Rev Neurosci 2004;5:553-564.

103. Yogeeswari P, Ragavendran JV, Thirumurugan R, Saxena A, Sriram D. Ion channels as important targets for antiepileptic drug design. Curr Drug Targets 2004;5:589-602.

104. Kwan P, Brodie MJ. Early identification of refractory epilepsy. N Engl J Med 2000;342:314-319.

105. Berkovic SF. Treatment with anti-epileptic drugs. Aust Fam Physician 2005;34:1017-1020.

106. Benbadis SR. Practical management issues for idiopathic generalized epilepsies. Epilepsia 2005;S9:125-132.

107. Camfield C, Camfield P. Management guidelines for children with idiopathic generalized epilepsy. Epilepsia 2005;S9:112-116.

108. Chiron C, Marchand MC, Tran A, et al. Stiripentol in severe myoclonic epilepsy in infancy: a randomized placebo-controlled syndrome-dedicated trial. Lancet 2000;356:1638-1642.

109. Guerrini R, Dravet C, Genton P. Lamotrigine and seizure aggravation in severe myoclonic epilepsy. Epilepsia 1998;39:508-512.

110. Tan NCK, Berkovic SF. Prediction of drug resistance in epilepsy: not as easy as ABC. Lancet Neurol 2006;5:641-642.

111. Szoeke CEI, Newton M, Wood JM, et al. Update on pharmacogenetics in epilepsy; a brief review. Lancet Neurol 2006;5:189196. 